\title{
GNSS remote sensing of the Australian tropopause
}

\author{
Khandu ${ }^{1}$, Awange $\mathrm{JL}^{1}$, Wickert $\mathrm{J}^{2}$, Schmidt $\mathrm{T}^{2}$, Sharifi $\mathrm{MA}^{3}$, Heck $\mathrm{B}^{4}$, and Fleming $\mathrm{K}^{1}$. \\ ${ }^{1}$ Curtin University of Technology, GPO Box U1987, Perth WA 6845, Australia \\ (khandu2000@gmail.com; J.Awange@curtin.edu.au; K.Fleming@curtin.edu.au) \\ ${ }^{2}$ Department 1: Geodesy and Remote Sensing, German Research Center for Geosciences (GFZ), \\ Telegrafenberg, 14473 Potsdam, Germany (wickert@gfz-potsdam.de; tschmidt@gfz-potsdam.de) \\ ${ }^{3}$ Surveying and Geomatics Engineering Department, Faculty of Engineering, University of Tehran, \\ Tehran,Iran (sharifi@ut.ac.ir) \\ ${ }^{4}$ Geodetic Institute, Karlsruhe Institute of Technology, Engler-Strasse 7, D-76131, Karlsruhe \\ (heck@gik.uni-karlsruhe.de)
}

\begin{abstract}
Radio occultation (RO) techniques that use signals transmitted by Global Navigation Satellite Systems (GNSS) have emerged over the past decade as an important tool for measuring global changes in tropopause temperature and height, a valuable capacity given the tropopause's sensitivity to temperature variations. This study uses 45,091 RO data from the CHAMP (CHAllenging Minisatellite Payload, 80 months), GRACE (Gravity Recovery And Climate Experiment, 23 months) and COSMIC (Constellation Observing System for Meteorology, Ionosphere, and Climate, 20 months) satellites to analyse the variability of the tropopause's height and temperature over Australia. GNSS RO temperature profiles from CHAMP, GRACE, and COSMIC are first validated using radiosonde observations provided by the Bureau of Meteorology (Australia). These are compared to RO soundings from between 2001 and 2007 that occurred within 3 hours and $100 \mathrm{~km}$ of a radiosonde. The results indicate that RO soundings provide data of a comparable quality to radiosonde observations in the tropopause region, with temperature deviations of less than $0.5 \pm 1.5 \mathrm{~K}$. An analysis of tropopause height and temperature anomalies indicates a height increase over Australia as a whole of $c a .4 .8 \pm 1.3 \mathrm{~m}$ between September 2001 and April 2008, with a corresponding temperature decrease of $-0.019 \pm 0.007 \mathrm{~K}$. A similar pattern of increasing height/decreasing temperature was generally observed when determining the spatial distribution of the tropopause height and temperature rate of change over Australia. Although only a short period has been considered in this study, a function of the operating time of these satellites, the results nonetheless show an increase in the height of the tropopause over Australia during this period and thus may indicate regional warming. Several mechanisms could be responsible for these changes, such as an increase in the concentration of greenhouse gases in the atmosphere, and lower stratospheric cooling due to ozone loss, both of which have been observed during the last decades.
\end{abstract}

Keywords: Tropopause height, tropopause temperature, regional warming, radio occultation, GNSS, CHAMP, GRACE, COSMIC.

\footnotetext{
${ }^{1}$ Contact: J.Awange@curtin.edu.au
} 


\section{Introduction}

Climate change, as revealed by rising global temperatures and changes in rainfall patterns, has proved to be one of the most challenging issues facing society today. The Intergovernmental Panel on Climate Change (IPCC, 2007) assessment report points out that the rate of warming over the past 50 years is almost double that compared to the last 100 years. Australia is already believed to be experiencing the adverse impacts of climate change, with much of the country having been affected by drought for most of the last decade, resulting in the loss of livestock and degradation of agricultural lands, reduction in reserves of stored ground and dam water, bush fires and dust storms. While drought is a frequent feature of Australia's climate, this current dry period has in fact been made worse by increased temperatures (e.g. Nicholls, 2006; Murphy and Timbal, 2008; Ummenhofer et al., 2009). Hence, the need to understand the nature and magnitude of temperature change is a particularly pressing issue.

In an effort to understand and quantify the impact of rising temperatures, believed to result from increasing greenhouse gas concentrations in the atmosphere, the lapse-rate or thermal tropopause (called simply the tropopause in this study) has been shown to be sensitive to temperature changes in the lower atmosphere and is seen as an important measure of global climate change (e.g., Sausen and Santer, 2003; Santer et al., 2003; Schmidt et al., 2008). Global tropopause heights have displayed an upward trend in reanalysis (e.g., Santer et al., 2004) and radiosonde observations (e.g., Seidel and Randel 2006). According to Santer et al. (2003), human induced greenhouse gases have contributed $c a$. $80 \%$ of the global tropopause height increase between 1979 and 2001. However, the lack of vertical resolution in the radiosonde measurements and reanalyses prevents the tropopause region from being accurately identified. In addition, changes in the measurement systems used by satellites and radiosondes in response to evolving technologies may also affect our interpretation of these measurements (Melbourne et al., 1994).

A more versatile atmospheric remote sensing technique has been developed over the last two decades to monitor changes in tropopause height, making use of GNSS (Global Navigation Satellite Systems) signals in conjunction with Low-Earth Orbiting (LEO) satellites, such as the CHAllenging Mini-satellite Payload (CHAMP, launched 15.07.2000, Wickert et al., 2001) and the Gravity Recovery and Climate Experiment (GRACE, launched 17.03.2002; Wickert et al., 2005). This method, known as GNSS radio occultation (RO) or GNSS meteorology, has the potential to overcome problems related to the classical methods due to its high accuracy and vertical resolution ( $\sim .5$ to $1.5 \mathrm{~km})$, as well as its all weather global coverage (e.g. Melbourne et al., 1994; Ware et al., 1996; Nishida et al., 2000; Schmidt et al., 2005; Schmidt et al., 2008). Foelche et al. (2007) report that radio occultation data have the highest quality at altitudes between $8 \mathrm{~km}$ and $35 \mathrm{~km}$, and for this reason they are very useful for tropopause studies. The availability of such data for climate studies significantly increased as a result of the launch of the Constellation Observing System for 
Meteorology, Ionosphere, and Climate (COSMIC) satellites (launched 14.04.2006; Anthes et al., 2008).

While global tropopause height trends derived from GNSS RO have been presented in the literature (e.g. Schmidt et al., 2008), this study attempts to investigate the tropopause height and temperature trends over Australia during the 7 year period between September 2001 and April 2008 using three sources of GNSS RO data, namely the above mentioned CHAMP, GRACE and COSMIC satellites. The following section outlines the study area (the continent of Australia) within the context of these observations. We next discuss the data used in this study, including radiosonde data provided by the Australian Bureau of Meteorology (BoM). We then outline the analysis applied, including a comparison in the quality of the RO data to that found from the BoM radiosonde observations. The results are then presented, followed by their analysis and interpretation, with the findings summarised in the conclusion. 


\section{Study area}

Australia, because of its large spatial extent and strong vulnerability to drought, provides an excellent opportunity to study trends in tropopause heights and temperatures. While Australia has suffered from a long history of drought, the issue of global warming associated with climate change has worsened the current drought conditions (e.g. Nicholls, 2006; Murphy and Timbal, 2008; Ummenhofer et al., 2009). The trend in Australian temperatures has seen an increase of $0.09^{\circ} \mathrm{C} /$ decade between 1910 and 2006, with a value over double this $\left(0.19^{\circ} \mathrm{C} /\right.$ decade) for the period 1970 to 2006 (Murphy and Timbal, 2008). In light of these conditions, the analysis of tropopause parameters (e.g., temperature, height trends) has the potential to provide additional insight into climate change around Australia, due to the tropopause's sensitivity to temperature change in the troposphere and lower stratosphere (Sausen and Santer, 2003), made possible by the large number of evenly distributed GNSS RO data available over Australia (see Figure 1).

\section{[FIGURE 1]}




\section{Data used}

\subsection{Radiosonde data}

A radiosonde dataset from 2001-2007 was provided by the Australian Bureau of Meteorology (BoM). Currently, BoM maintains around 45 radiosonde stations, including 39 within Australia and offshore (see Figure 2). Most stations are located at the major airports, with very few stations within the centre of the continent. The radiosonde data provides atmospheric parameters (such as temperature and pressure profiles) at standard pressure levels (e.g., $850 \mathrm{hPa}, 700 \mathrm{hPa}$, etc.). In this study, the radiosonde data were used as the basic data for validating the GNSS RO data, as described below.

\section{[FIGURE 2]}

\subsection{CHAMP RO data}

The CHAMP satellite has provided around 108 uniformly distributed atmospheric profiles per month in the Australian region (see Figure 3) during the period between September 2001 and April 2008 (80 months; Wickert et al., 2009), although data is not available for July 2006. The processed RO data are obtained from the German Research Center for Geosciences (GFZ, Potsdam, Germany) in the form of what is termed CHAMP Level 3 data (version 005). These contain profiles inverted using the Abel transformation (e.g., Awange and Grafarend, 2005, pp. 225) of refractivity derived from the vertical profiles of bending angles (see below) with a vertical resolution of $200 \mathrm{~m}$. From the 16 available atmospheric parameters in the Level 3 data (e.g., temperature, pressure, bending angles), only altitude, occulting position of the GNSS signal and temperature were used in this study.

\subsection{GRACE RO data}

GRACE consists of two satellites orbiting the Earth in tandem, separated by ca. $220 \mathrm{~km}$ in a near-polar orbit at an altitude of $c a .400 \mathrm{~km}$, and is expected to remain operational until ca. 2013. RO from the GRACE satellites is possible due to their operation of high-quality Blackjack GPS receivers installed on both spacecraft (provided by Jet Propulsion Laboratory, JPL; Schmidt et al., 2004). The GRACE satellites have provided continuous RO data since May 22, 2006, available in a form equivalent to the CHAMP Level 3 data (Wickert pers. com.) in that it contains Abel inverted profiles of temperature, pressure, etc., with a vertical resolution of $200 \mathrm{~m}$. The GRACE satellites recorded 1975 high-quality atmospheric profiles between 2006 and 2007, with an average of about 99 profiles per month, although the distribution of the GRACE measurements is not as good as the CHAMP data (see Figure 1).

\subsection{COSMIC RO data}


GNSS limb sounding attained a much greater capacity following the successful launch of the six COSMIC satellites in 2006, whose main objective is to measure vertical profiles of temperature, pressure, and water vapour in the neutral atmosphere and electron density in the ionosphere (Cheng et al., 2006). The difference between COSMIC RO data and that from the two previous missions is the improved data quality with higher yields in the lower atmosphere. This is enabled by the use of the OpenLoop (OL) signal tracking technique by the Blackjack GPS receiver (Wickert et al., 2009), which allows for the tracking of rising occultation and hence deeper penetration into the lower atmosphere.

Level 2 COSMIC data is provided by UCAR (University Cooperation for Atmospheric Research) and NSPO (National Space Organisation, Taiwan), and contains Abel inverted profiles of refractivity with air temperature, water vapour, air pressure, height above mean sea level, and location. As with the CHAMP and GRACE data, only altitude, temperature and occultation positions are used in this study. Between April 2006 and March 2008, the COSMIC satellites recorded some 34644 atmospheric profiles (see Figure 3), with an average of 1443 profiles per month.

\section{[FIGURE 3]}




\section{4. $\quad$ Processing methods}

\subsection{GNSS Radio Occultation}

The GNSS radio occultation (RO) technique is based on precise dual-frequency measurements (L-band) made by a GNSS receiver onboard a LEO satellite such as those already discussed, during the rising and setting of a GNSS satellite. The GNSS signals received by the LEO satellites will be delayed and their ray paths slightly bent while passing through different layers of the atmosphere. Figure 4 shows the geometry of the RO technique and how the ray paths bend during an occultation event. The delay in the signal received by the LEO satellite is observed as a difference in phase and amplitude, from which the phase delay is inverted to atmospheric refractivity using the Abel transformation. The theory of GNSS RO is discussed in detail in, e.g., Awange and Grafarend (2005), Gorbunov et al., (1996), Melbourne et al., (1994), Steiner (1998), Tsuda et al., (1998), and Wickert (2002). The relationship between the bending angle $\alpha$ (caused by the atmospheric refraction, Figure 4), the impact parameter $a$ (the radial distances to the start and end of the bending of the signal), and refractive index $n$ is given as (Awange and Grafarend, 2005, eqn. 13.2)

$$
\alpha(a)=2 a \int_{r=r_{o}}^{r=\infty} \frac{1}{\sqrt{n^{2} r^{2}-a^{2}}} \frac{d\{\ln (n)\}}{d r} d r
$$

The right-hand side of (1) is then inverted using the Abel transformation to express the bending angle (inferred from the position and velocity of the GNSS and LEO satellites) as a function of the parameter $a$ (Awange and Grafarend, 2005, eqn. 13.3):

$$
n\left(r_{o}\right)=\exp \left[\frac{1}{\pi} \int_{a=a_{o}}^{a=\infty} \frac{\alpha(a)}{\sqrt{a^{2}-a_{o}^{2}}} d a\right]
$$

where $r_{o}$ is the radius from the Earth's centre to the height in question. Atmospheric parameters such as temperature, pressure and air density are computed from the refractivity $N$, which is related to the refractive index $n$ by (Awange and Grafarend 2005, eqn. 13.4):

$$
N=(n-1)^{6}=77.6 \frac{P}{T}+3.73 \times 10^{5} \frac{P_{w}}{T^{2}}-40.3 \times 10^{6} \frac{n_{e}}{f^{2}}+1.4 w
$$

where $P$ is the air pressure in mbar, $T$ is the air temperature in $\mathrm{K}, P_{w}$ is the water vapour partial pressure in mbar, $n_{e}$ is the electron density per cubic meter in number of electrons $/ \mathrm{m}^{3}$, $f$ is the transmitter frequency in $\mathrm{Hz}$, and $w$ is the liquid water content in $\mathrm{g} / \mathrm{m}^{3}$. 


\section{[FIGURE 4]}

\subsection{Validation of GNSS RO temperature profiles}

Temperature profiles from the GNSS RO observations made by the considered spacecraft (CHAMP, GRACE, and COSMIC) were compared to those from the radiosonde observations provided by BoM for the period between 2001 and 2007. The validation method was based on comparing RO and radiosonde measurements that are separated spatially by 100 $\mathrm{km}$ or less and temporally by 3 hours or less (see, e.g. Schmidt et al., 2005), these values being used since atmospheric weather is likely to remain nearly constant over such scales. Temperatures are compared at 14 standard pressure levels $l$ between 850 and $20 \mathrm{hPa}$. The mean temperature deviation $\overline{\Delta T(l)}$ at each pressure level and its corresponding standard deviation $\sigma_{\Delta T}(l)$ are obtained using (Wickert, 2004)

$$
\overline{\Delta T(l)}=\sum_{i=1}^{M(l)} T_{D(\text { CHAMP })}(i, l)-T_{R S}(i, l)
$$

and

$$
\sigma_{\Delta T}(l)=\sqrt{\frac{1}{M(l)-1} \sum_{i=1}^{M(l)}\left(T_{D(C H A M P)}-T_{R S}(i, l)\right)^{2}}
$$

where $\mathrm{M}(l)$ denotes the number of data points per pressure level, $i$ is the individual $\mathrm{RO}$ and radiosonde data, $T_{D(\text { CHAMP) }}$ is the temperature derived from the satellite data, and $T_{R S}$ is the temperature given by the radiosonde measurements. In this analysis, any temperature deviations obtained using equation (4) that were greater than $20 \mathrm{~K}$ were discarded to reduce the influence of outliers.

\subsection{Derivation and analysis of tropopause heights and temperatures}

The extraction of tropopause heights and temperatures from the GNSS RO profiles was based on the thermal definition provided by WMO (1957). WMO (1957) defines the tropopause as "the lowest level at which the lapse-rate decreases to $2 \mathrm{~K} / \mathrm{km}$ or less, provided that the averaged lapse-rate between this level and all other higher levels within $2 \mathrm{~km}$ does not exceed $2 \mathrm{~K} / \mathrm{km}$ ”. Only the first lapse-rate tropopause (LRT) is considered here, although multiple tropopauses are observed in the mid-latitudes, polar regions and even in the tropics (e.g., Schmidt et al., 2005; Seidel and Randel 2006). The radiosonde datasets are not used for the trend analysis and hence are not applied to the height and temperature computations. The 
lapse-rate $\Gamma\left(z_{i}\right)$ was computed between $500 \mathrm{hPa}$ and $70 \mathrm{hPa}$, corresponding to a mean altitude of about $6 \mathrm{~km}$ and $19 \mathrm{~km}$, and is given by (Schmidt et al., 2005):

$$
\Gamma\left(z_{i}\right)=-\frac{\delta T}{\delta z}=\frac{T_{i+1}-T_{i}}{z_{i+1}-z_{i}}
$$

where $T$ and $z$ are the temperatures and heights above mean sea level, respectively. According to WMO (1957), if $\Gamma\left(z_{i}\right)>\Gamma_{W M O}$, where $\Gamma_{W M O}=-2 \mathrm{~K} / \mathrm{km}$, then following conditions are considered:

1. Is the mean lapse-rate between $z_{i}$ and $\left(z_{i}+2 \mathrm{~km}\right)$ larger than $\Gamma_{W M O}$ ?

2. If it satisfies the above condition, the mean lapse-rate between the layers $\left(z_{i+1}, z_{i}\right)$ , $\left(z_{i+2}, z_{i+1}\right)$, and $\left(z_{i+3}, z_{i+2}\right)$ should be greater than $\Gamma_{W M O}$, whereas the mean lapserate between the layers $\left(z_{i}, z_{i-1}\right),\left(z_{i-1}, z_{i-2}\right)$, and $\left(z_{i-2}, z_{i-3}\right)$ should be less than $\Gamma_{\text {WMO }}$.

If these two conditions are fulfilled, then the $\operatorname{LRT}\left(z_{i}\right)$ corresponding to that lapse-rate is chosen and the other parameters (such as temperature, pressure, position) are then determined.

Since the tropopause height is strongly dependent on latitude, Australia $\left(8^{\circ} \mathrm{S}-46^{\circ} \mathrm{S}\right)$ is divided into three different zones (see Table 1) to determine where tropopause height has changed the most. The means and standard deviations associated with each zone are calculated for each month from September 2001 to April 2008 for the CHAMP RO data. For the COSMIC RO data, although it is available from April 2006 to March 2008, the tropopause heights are only computed from May 2006 due to the poor data coverage for April 2006. Data screening is based on the standard deviations of the means, with data with more than three times the standard deviation for each zone's month being considered outliers and discarded. Monthly anomaly time series are computed from the differences between the monthly and annual zonal means. The linear trend estimated is based on the height and temperature anomalies computed from the annual means.

\section{[TABLE 1]}




\section{Results}

\subsection{Validation of RO temperature profiles}

Before employing the conditions outlined above to determine the LRT parameters, it is necessary to ensure that the quality of the RO data was compatible to radiosonde data and hence be of sufficient quality for climate-change studies. For example, Schmidt et al. (2005) compared CHAMP temperature data with nearby radiosonde observations (within $300 \mathrm{~km}$ spatially and $3 \mathrm{hrs}$ temporally) and found deviations of less than $1 \mathrm{~K}$ for elevations between $9.5 \mathrm{~km}$ and $30.8 \mathrm{~km}$.

Figure 5 compares examples of the CHAMP, COSMIC and GRACE temperature profiles with the profiles from the closest radiosonde observations. The radiosonde launched from Learmonth Airport $\left(22.24^{\circ} \mathrm{S}, 114.09^{\circ} \mathrm{E}\right)$ on the $14^{\text {th }}$ June 2005 (Figure 5a) was within 70 $\mathrm{km}$ and 40 minutes of the CHAMP measurement, the radiosonde launched from Hobart Airport $\left(42.8389^{\circ} \mathrm{S}, 147.4992^{\circ}\right)$ on the $20^{\text {th }}$ December 2006 (Figure 5b) was within $12 \mathrm{~km}$ and 1.25 hours of the COSMIC measurement, while the profile from the radiosonde launched from Weipa Aerodrome in North Queensland $\left(12.6778^{\circ} \mathrm{S}, 141.9208^{\circ} \mathrm{E}\right)$ on the $8^{\text {th }}$ September 2006 (Figure 5c) was within $92 \mathrm{~km}$ and 1.25 hours of the corresponding GRACE measurements. A visual inspection of Figure 5 indicates that the COSMIC RO temperature profile agrees better with the corresponding radiosonde profile than those from the other two satellites, with almost no deviation within the altitude range of the radiosonde data. The temperature profiles from CHAMP satellite have been shown, e.g., by Schmidt et al. (2004), to agree well in the upper troposphere and lower stratosphere, while the GRACE profile agrees well with the corresponding radiosonde measurement above $8 \mathrm{~km}$, although below this altitude it is affected by water vapour, as are the CHAMP profiles.

\section{[FIGURE 5]}

\subsection{Comparison results}

Figure 6 presents how the RO and radiosonde measurements compare for the three satellite missions over Australia, as well as the numbers of profiles that were employed. For the CHAMP satellite, 80 profiles (Figure 6d) from September 2001 to December 2006 are found to be within the spatial (100 km) and temporal (3 hours) limits defined above, allowing their comparison with a radiosonde profile. We note for this case (Figure 6a) a temperature bias of less than $1 \mathrm{~K}$ for the complete height interval between $9 \mathrm{~km}$ and $26 \mathrm{~km}$, with a standard deviation of less than $2 \mathrm{~K}$. Between $11 \mathrm{~km}$ and $26 \mathrm{~km}$, the bias is less than $0.5 \mathrm{~K}$ with a standard deviation of between 1 and $2 \mathrm{~K}$. As commented upon before, the CHAMP temperature estimates in the lower troposphere (altitude $<7.5 \mathrm{~km}$ ) are affected significantly by water vapour, which is neglected during the Abel's transformation (Wickert, 2004; Kuo et 
al., 2005; Foelche et al., 2007), with the bias and standard deviations being greater at these altitudes.

For the GRACE RO data (Figure 6b), only 18 profiles (Figure 6d) from January 2006 to October 2007 were found to be within the defined spatial and temporal range. Nevertheless, the GRACE RO profiles appear to agree with the radiosonde observations. The positive bias in the GRACE temperatures could be due to the smaller number of GRACE profiles meeting the required criteria, although it is still less than $1 \mathrm{~K}$ with standard deviations of less than $3 \mathrm{~K}$ between an altitude range of 9 and $20 \mathrm{~km}$. Below $9 \mathrm{~km}$, like the CHAMP temperature data, the GRACE temperature profiles are strongly affected by water vapour.

COSMIC RO data from April 2006 to December 2006 were used for the comparisons with radiosonde observations, with 54 profiles (Figure 6d) found to meet the spatial and temporal limits outlined above. The results of the comparisons (Figure 6c) indicate deviations of less than $0.5 \mathrm{~K}$ over the height interval between $10.7 \mathrm{~km}$ and $24 \mathrm{~km}$, with standard deviations of less than $2 \mathrm{~K}$.

Comparing the profiles from the three missions, it can be seen that the bias between CHAMP and COSMIC RO temperatures with the radiosonde values closely agree between $10.7 \mathrm{~km}$ and $25 \mathrm{~km}$, being less than $0.5 \mathrm{~K}$ over this range. CHAMP RO data has lower standard deviation than the COSMIC data between $10 \mathrm{~km}$ and $18 \mathrm{~km}$, with values of less than 1.5K. Below $7.5 \mathrm{~km}$, the CHAMP temperatures show a large negative bias whereas the bias from the COSMIC data remains constant. The GRACE temperature data do not agree as well with the other two RO datasets, with a positive bias above $12.5 \mathrm{~km}$. Again, this may be due to the limited amount of data used in this analysis, i.e., 18 compared to 80 for CHAMP and 54 for COSMIC. From amongst the three RO datasets, the COSMIC temperature data displays the lowest variability in their standard deviations, while CHAMP and GRACE temperatures have the highest standard deviation below $10 \mathrm{~km}$.

\section{[FIGURE 6]}

\subsection{Tropopause heights and temperatures}

The tropopause heights and temperatures from 2001 to 2008 are provided in Figures 7 and 8 . The heights and temperatures are plotted monthly and annually to assess any changes between these periods. Figure 7 shows the mean tropopause heights (Figure 7a) and temperatures (Figure 7b) over Australia for the period between September 2001 and April 2008 as estimated by CHAMP RO data. The mean tropopause height is found to be $c a$. 16 $\mathrm{km}$ with a corresponding mean temperature of ca. $200 \mathrm{~K}$, with both showing a fairly clear cyclic pattern. For the values derived from the COSMIC RO data (Figure 8) for the period between May 2006 to March 2008, the cyclic pattern is still clear, but as well there is some indication of an upward trend in the tropopause heights (Figure 8a) with a corresponding 
decrease in temperature (Figure 8b), although this must be treated with caution as the time series is much shorter. A more detailed discussion of the trends is provided in Section 5.6.

\section{[FIGURE 7]}

\section{[FIGURE 8]}

\subsection{Latitudinal and Longitudinal Variations}

The maximum tropopause height has been estimated using radiosondes and reanalysis to occur at about $17 \mathrm{~km}$ at the equator (e.g., Honika 1998; Santer et al. 2004), decreasing towards the mid-latitudes. The LRT heights derived from radiosonde data (Seidel and Randel, 2006) were estimated to be between $16.6 \mathrm{~km}$ (near the equator) and $9 \mathrm{~km}$ in the polar zones, whereas heights as great as $18 \mathrm{~km}$ have been found using GNSS RO techniques (e.g., Kishore et al., 2006). As commented upon before, tropopause parameters display a strong latitudinal dependence, as can be seen in Figure 9a. The height of the tropopause over Australia reaches as high as $18.6 \mathrm{~km}$ in the tropical zone and as low as $9 \mathrm{~km}$ in the midlatitude regions, with the largest variations seen in the mid-latitudes (from about $30^{\circ} \mathrm{S}-45^{\circ} \mathrm{S}$ ) with an average standard deviation of $2 \mathrm{~km}$, and greater in the subtropical jet stream areas (around $30^{\circ} \mathrm{S}$ to $35^{\circ} \mathrm{S}$ ), which cover the southern half of Australia. It is noted that between $15^{\circ} \mathrm{S}$ and $25^{\circ} \mathrm{S}$, tropopause heights appear to be higher than what is found near the equatorial region $\left(8^{\circ} \mathrm{S}-15^{\circ} \mathrm{S}\right)$. The tropopause temperature, as seen in Figure 9b, remains almost constant for latitudes up to $18^{\circ} \mathrm{S}$ and then increases significantly with increased creased variability the further south.

\section{[FIGURE 9]}

\subsection{Seasonal Variations}

The behaviour of the tropopause with respect to the summer and winter seasons has also been studied with respect to the different data sets. Figure 10 shows the mean seasonal tropopause height for summer (December 2006 to February 2007, Figure 10a,c) and winter (June to August, 2007, Figure 10b,d) as estimated by CHAMP (Figure 10a,b) and COSMIC (Figure 10c,d) RO data. During summer, the tropopause height reaches up to $17 \mathrm{~km}$ or higher in most parts of the Australian inland, while in winter, the tropopause height decreases by more than $4 \mathrm{~km}$ in the mid-latitudes $\left(30^{\circ} \mathrm{S}-45^{\circ} \mathrm{S}\right)$. Comparing the CHAMP and COSMIC results, the structure of the tropopause height as revealed by COSMIC shows a slightly higher tropopause height in the Australian inland while in the far south it shows a slightly lower height. In winter, the variation is almost the same for both datasets.

Figure 11 shows similar results for tropopause temperatures derived from CHAMP (Figure 11a,b) and COSMIC (Figure 11c,d) RO data for summer (Figure 11a,c) and winter 
(Figure 11b,d). It can be seen that CHAMP temperatures are warmer in summer than in winter and are generally cooler compared to those of COSMIC during the same period. It should also be added that for both the height and temperature values, more spatial variability can be discerned from the COSMIC dataset because of its higher density.

\section{[FIGURE 10]}

\section{[FIGURE 11]}

\subsection{Trend analysis and results}

The resulting temporal trends in the tropopause heights and temperatures for the investigation period (September 2001 to April 2008) for the three zones and for Australia as a whole are investigated using two different combinations of the RO data:

1. A combination of CHAMP (September 2001 to April 2008) and COSMIC (May 2006 to March 2008);

2. The CHAMP (September 2001 to April 2008) time series, with data from COSMIC for July 2006 (since there was no data from CHAMP at this time).

This was done to determine if there was any dependence upon the actual satellite whose data was used. For the time series studies, we neglect the GRACE data owing to the relatively small number of profiles.

Trends were determined by fitting a straight line through the data after averaging the readings (e.g. heights) for each season and then differencing the seasonal average from their monthly reading. This is done to remove the effect of the cyclic trends in the data that may disrupt the linear terms. Table 2 summarises the changes determined from the time series of the height and temperature anomalies estimated by the combined CHAMP and COSMIC RO data, with the time series presented in Figure 12 (height anomalies) and Figure 13 (temperature anomalies). It can be seen from these figures that it is difficult to visually identify a trend in any of the time series. However, after fitting a linear trend, we find (see Table 2) that there is a small increase in the overall regional tropopause height over Australia of $4.8 \pm 1.3 \mathrm{~m}$, with a corresponding temperature decrease of $-0.019 \pm 0.007 \mathrm{~K}$ over the 80 month study period. These variations vary over the country, ranging from $2.8 \pm 1.2 \mathrm{~m}$ over the tropics, to $0.9 \pm 1.2 \mathrm{~m}$ in the mid-latitudes, with the corresponding temperature changes ranging from $-0.016 \pm 0.005 \mathrm{~K}$ in the tropics to $0.019 \pm 0.007 \mathrm{~K}$ in the mid-latitudes. The larger tropopause height change values in the tropical zone or transition zone (Schmidt et al., 2008) are influenced strongly by the subtropical jet streams.

\section{[TABLE 2]}




\section{[FIGURE 12]}

\section{[FIGURE 13]}

Changes in the tropopause height and temperature anomalies constructed from CHAMP RO data (September 2001 to April 2008, plus the July 2006 COSMIC data) were also determined and are presented in Table 3. As one would expect, similar trends are noticed, except in the mid-latitude zones where there is a small decrease in the tropopause height $(-2.4$ $\pm 1.6 \mathrm{~m}$ ) with corresponding temperature increase of $0.05 \pm 0.014 \mathrm{~K}$. Therefore, we have not included a figure with these results.

\section{[TABLE 3]}

\subsection{Comparison with the global tropopause height trend}

The global tropopause height study shown in Schmidt et al. (2008) described an increase of 26 to $44 \mathrm{~m} /$ decade with trend errors varying from 19 to $21 \mathrm{~m}$. They used CHAMP RO data between May 2001 and December 2007 (80 months). Significant increases in the global tropopause height have occurred with most of the contributions coming from the subtropical regions. From our studies, we find a regional tropopause height increase of 4.7 to $4.8 \mathrm{~m}$ during the 80 month period between September 2001 and April 2008, equivalent to 7.0 to $7.2 \mathrm{~m} /$ decade with a trend error varying from $0.6 \mathrm{~m}$ to $16 \mathrm{~m}$. Although the trend results are smaller than that estimated in Schmidt et al. (2008), the results nonetheless show an increasing trend, the main differences being seen in the tropics where Schmidt et al. (2008) estimated a decrease in the tropopause height whereas in this study an upward trend was found.

Similarly, the global tropopause height trend estimated from radiosonde observations (Seidel and Randel, 2006) shows an upward trend (64 \pm 21 m/decade) from 1984 until 2004. The corresponding temperature trend was $-0.41 \pm 0.09 \mathrm{~K} /$ decade. The temperature trends estimated in this study are much lower than has been established for the global tropopause (0.03 $\pm 0.01 \mathrm{~K} /$ decade). In the southern subtropics, Seidel and Randel (2006) observed an increase in the tropopause height of $121 \mathrm{~m}$ /decade. The results from GNSS RO data used in this study likewise show an increasing trend, although much smaller value, i.e., 4.2 to 5.1 $\mathrm{m} /$ decade.

How these rates vary over all of Australia is illustrated in Figure 14, which shows the rate of change of (a) tropopause heights and (b) tropopause temperatures derived from the combined CHAMP and COSMIC data set between September 2001 and April 2008. There is a general autocorrelation between the two sets of results as one would expect (e.g. increasing height/decreasing temperature). Much of Australia displays trends of 0 to $0.1 \mathrm{~km} / \mathrm{year}$ of 
Climatic Change, revised manuscript

increasing tropopause height, with a corresponding temperature decrease of 0 to $-0.3 \mathrm{~K} / \mathrm{year}$.

These values are much higher than those presented earlier (Tables 2 and 3). This is likely to be because the values in Tables 2 and 3 represent latitudinal zonal averages.

\section{[FIGURE 14]}




\section{Analysis}

It has been shown in Section 3 that RO data distribution over Australia is very good, except for the far tropical regions (between $8^{\circ} \mathrm{S}$ and $15^{\circ} \mathrm{S}$ ). The COSMIC satellite alone contributes about 1443 atmospheric profiles per month, providing a very good opportunity for monitoring the tropopause over Australia. The temperature profiles from CHAMP and COSMIC RO measurements agree with radiosonde measurements within less than $1 \pm 1.5 \mathrm{~K}$ in the tropopause region. The best agreements are seen between $10 \mathrm{~km}$ and $19 \mathrm{~km}$ height with measurements accurate to better than $0.5 \pm 1.5 \mathrm{~K}$. Due to a very limited number of GRACE profiles found within a $100 \mathrm{~km}$ and 3 hours interval from the nearest radiosonde measurements, the differences between the two measurement types are quite large compared to those from the other satellites.

The regional tropopause structure (height and temperature trends) have been analysed using 80 months (September 2001- April 2008) of CHAMP data and 23 months (May 2006 March 2008) of COSMIC RO data combined (Table 2), as well as using the CHAMP data alone, except for the inclusion of one month (July 2006) of COSMIC data (Table 3). This study shows a tropopause height increase for Australia as a whole using the combined data set of $4.8 \pm 1.3 \mathrm{~m}$ and a temperature change of $-0.019 \pm 0.007 \mathrm{~K}$ for the study period. Similar results were obtained using the CHAMP +1 month of COSMIC data time series $(4.7 \pm 1.1 \mathrm{~m}$ and $-0.017 \pm 0.005 \mathrm{~K})$. Large standard errors are a result of greater variation of data as most of the Australian region is situated in the subtropics and mid-latitudes where the data variations are largest. The regional trend computed from the combination of CHAMP and COSMIC data is affected by the lower height values resulting from the COSMIC RO data. The increasing trend is much smaller than that estimated by Schmidt et al. (2008) and Seidel and Randel (2006), although the difference in results needs to consider the use of different data sets (CHAMP and radiosonde) and time scales (80 months and 25 years). Seidel and Randel (2006) used only four radiosonde stations in Australia to compute the global tropopause and temperature trends, which would produce a large difference in the estimated height and temperature trends when compared to the RO results. Nevertheless, the results indicate an upward trend in the tropopause height with decreasing temperature trend over the 7 year study period. 


\section{Conclusions}

Rising tropospheric temperatures due to global warming increases the height of the tropopause, therefore, information about tropopause height-change trends potentially provides a means for monitoring regional warming. This study has indicated that the GNSS RO atmospheric profiles of the tropopause temperatures and heights match those from radiosonde measurements (i.e., temperature measurements accurate to $1 \pm 1.5 \mathrm{~K}$ in the tropopause region) and could therefore be suitable for use in the analysis of regional climate change. The analysis of the tropopause over Australia shows a similar trend as that indicated in global studies, despite a shorter time frame and the regional scope of the analysis. The analysis here provides possible evidence for regional warming trends, therefore warranting more detailed studies. Even with the short time frame of data set, both the anomaly and rate of change analyses indicate an increase in tropopause height over the 80 month study period, which could possibly be caused by increasing greenhouse gases in the lower atmosphere. The increase of the tropopause height is largely seen in the tropics and subtropics, whereas there is a decrease in the mid-latitude region.

In order to establish a more versatile tropopause trend analysis the following recommendations are given for future studies:

- Estimate tropopause height and temperature trend using all available RO measurements from CHAMP, GRACE, and COSMIC satellites with multi-decadal observations from radiosondes. In this study, the amount of GRACE data was limited compared to CHAMP and COSMIC data.

- Study the correlation between tropospheric (and stratospheric) temperature and tropopause temperature to relate the warming trend in the troposphere (cooling trend in the stratosphere) to the tropopause temperature.

- Integration of GNSS RO data into climatological study models will provide an enhancement of this technique.

It has been discussed in the literature that trends in the tropopause height is a useful indication of climate change, both in terms of tropospheric warming due to increase greenhouse gas concentrations, and the cooling of the stratosphere arising from ozone depletion. Hence, having the capacity to accurately monitor tropopause characteristics at an adequate resolution has the potential to provide additional constraints. This study provides an indication of the capability of undertaking a long-term study using multi-decadal records of radiosonde observations and GNSS RO measurements. Given that the COSMIC satellites are set to last until 2014-2015, there is the possibility of gaining another sufficiently long time series to study temperature trends in the upper atmosphere. 
Climatic Change, revised manuscript

\section{Acknowledgements}

The authors would like to thank Dr. Paul Tregoning of ANU, the two reviewers as well as the editor for their valuable comments and suggestions which have significantly enhanced the quality of this manuscript. They are further grateful to GFZ and UCAR for the provision of the data. Khandu acknowledges the support of a Royal Government of Bhutan scholarship that allowed him to undertake this work. J.L. Awange acknowledges the financial support of a Curtin Research Fellowship and the Alexander von Humboldt (Ludwig Leichhardt Memorial Fellowship) Foundation that supported his time at Curtin and Karlsruhe universities. K. Fleming acknowledges the support of the ARC Discovery Project "Environmental geodesy: variations of sea level and water storage in the Australian region" (DP087738). 


\section{References}

Anthes RA, Bernhardt PA, Chen Y, Cucurull L, Dymond KF, Ector D, Healy SB, Ho S-P, Hunt DC, Kuo Y-H, Liu H, Manning K, McCormick C, Meehan TK, Randel WJ, Rocken C, Schreiner WS, Sokolovskiy SV, Syndergaard S, Thompson TK, Trenberth KE, Wee T-K, Yen NL and Zeng Z (2008) The COSMIC/FORMOSAT-3 Mission: Early Results, Bulletin of the American Meteorological Society, 89, 313-333.

Anthes RA, Rockens C and Kuo Y-H. (2000) Applications of COSMIC to Meteorology and Climate, Terrestrial, Atmospheric and Oceanic Sciences, 11, 115-156.

Awange JL and Grafarend EW (2005) "GPS Meteorology in Environmental Monitoring", Solving Algebraic Computational Problems in Geodesy and Geoinformatics, Springer, Berlin, pp. 217-244.

Cheng CZ, Kuo Y-H, Anthes RA and Wu L (2006) Satellite Constellation Monitors Global and Space Weather. EOS, Transactions American Geophysical Union, 87, 10.1029/2006EO170003.

Foelsche U, Borsche M, Steiner AK, Gobiet A, Pirscher B, Kirchengast G, Wickert J and Schmidt T (2007) Observing upper troposphere-lower stratosphere climate with radio occultation from the CHAMP satellite, Climate Dynamics, 31, 49-65.

Gorbunov ME, Gurvich AS and Bengtsson L (1996) Advanced algorithms of inversion of GPS/MET satellite data and their application to the reconstruction of temperature and humidity. Max-Plunk-Institut fur Meteorologie, Hamburg, Germany.

Honika PK (1998) Statistics of the global tropopause pressure, Monthly Weather Review, 126, 3303-3325.

IPCC (2007) IPCC Fourth Assessment Report: Climate Change 2007: The Physical Science Basis, Intergovernmental Panel on Climate Change. (http://www.ipcc.ch/).

Karl TR, Hassol SJ, Miller CD and Murray WL (2006) Temperature trends in the lower atmosphere: Steps for understanding and reconciling differences. A Report by the Climate Change Science Program and the Subcommittee on Global Change Research, Washington, DC.

Kishore P, Namboothiri SP, Igarashi K, Jiang JH and Ao CO (2006) Climatological characteristics of the tropopause parameters derived from GPS/CHAMP and GPS/SACC measurements, Journal of Geophysical Research, 111, 10.1029/2005JD006827. 
Kuo Y-H, Schreiner WS, Wang J, Rossiter DL and Zhang Y (2005) Comparison of GPS Radio occultation soundings with radiosonde, Geophysical Research Letters, 32, 10.1029/2004GL021443.

Melbourne WG, Davis ES, Hajj GA, Hardy KR, Kursinski ER, Meehan TK, Young LE and Yunck TP (1994) The application of spaceborne GPS to atmospheric limb sounding and global change monitoring, JPL Publications, 94-18.

Murphy BF and Timbal B (2008) A review of recent climate variability and climate in southeastern Australia, International Journal of Climatology, 28, 859-879.

Nichols N (2006) Detecting and attributing Australian climate change: a review, Australian Meteorological Magazine, 55, 199-211.

Nishida M, Shimizu A, T. Tsuda, Rocken C and Ware RH (2000) Seasonal and longitudinal variations in the tropical tropopause observed with the GPS occultation technique (GNSS/MET), Journal of the Meteorological Society of Japan, 78, 691-700.

Santer BD, Wehner, MF, Wigley TML, Sausen R, Meehl GA, Taylor KE, Ammann C, Arblaster J, Washington WM, Boyle JS and Brüggemann W (2003) Contributions of anthropogenic and natural forcing to recent tropopause height changes, Science, 301, 479-483.

Santer BD, Wigley TML, Simmons AJ, Kallberg PW, Kelly GA, Uppala SM, Ammann C, Boyle JS, Brüggemann W, Doutriaux C, Fiorino M, Mears C, Meehl GA, Sausen R, Taylor KE, Washington WM, Wehner MF and Wentz FJ ( 2004) Identification of anthropogenic climate change using a second-generation reanalysis, Journal of Geophysical Research, 109, 10.1029/2004JD005075.

Sausen R and Santer BD (2003) Use of changes in tropopause height to detect influences on climate, Meteorologische Zeitschrift, 12, 131-136.

Schmidt T, Wickert J, Beyerle G and Heise S (2008) Global tropopause height trends estimated from GPS radio occultation data, Geophysical Research Letters, 35, 10.1029/2008GL034012.

Schmidt T, Heise S, Wickert J, Beyerle G and Reigber C (2005) GPS radio occultation with CHAMP and SAC-C: global monitoring of thermal tropopause parameters, Atmospheric Chemistry and Physics Discussions, 5, 1473-1488.

Seidel DJ and Randel WJ (2006) Variability and trends in the global tropopause estimated from radiosonde data, Journal of Geophysical Research, 111, 10.1029/2006JD007363. 
Steiner AK (1998) High resolution sounding of key climate variabilities using the radio occultation technique. Dissertation. Institution for Meteorology and Geophysics, University of Graz.

Tsuda T, Heki K, Miyazaki S, Aonashi K, Hirahara K, Tobita M, Kimara F, Tabei T, Matsushima T, Kimura F, Satomura M, Kato T and Naito I (1998) GPS meteorology project of Japan - Exploring frontiers of geodesy, Earth Planets Space, 50(10), i-iv.

Ummenhofer CC, England MH, McIntosh PC, Meyers GA, Pook MJ, Risbey JS, Gupta AS and Taschetto AS (2009) What causes southeast Australia's worst droughts?, Geophysical Research Letters, 36, 10.1029/2008GL036801.

Ware R, Exner M, Feng D, Gorbunov M, Hardy K, Herman B, Gorbunov M, Sokolovskiy S, Hardy Y, Kuo Y, Zou X, Trenbeth K, Meehan T, Melbourne W and Businger S (1996) GPS sounding of the atmosphere from Low Earth Orbit: Preliminary Results, Bulletin of the American Meteorological Society, 77, 19-40.

Wickert J, Reigber C, Beyerle G, König R, Marquardt C, Schmidt T, Grunwald L, Galas R, Meehan TK, Melbourne WG and Hocke K (2001) Atmospheric sounding by GPS radio occultation: First results from CHAMP, Geophysical Research Letters, 28, 10.1029/2001GL013117.

Wickert J, Schmidt T, Beyerle G, König R, Reigber Ch and Jakowski N (2004) The radio occultation experiment aboard CHAMP: Operational data analysis and validation of atmospheric profiles, Journal of the Meteorological Society of Japan, 82(1B), 381-395.

Wickert J, Beyerle G, König R, Heise S, Grunwaldt L, Michalak G, Reigber Ch and Schmidt, $\mathrm{T}$ (2005) GPS radio occultation with CHAMP and GRACE: A first look at a new and promising satellite configuration for global atmospheric sounding, Annales Geophysicae, 23(3), 653-658.

Wickert J, Michalak G, Schmidt T, Beyerle G, Cheng CZ, Healy SB, Heise S, Huang C-Y, Jakowski N, Köhler W, Mayer C, Offiler D, Ozawa E, Pavelyev AG, Rothacher M, Tapley B and Arras C (2009) GPS radio occultation: Results from CHAMP, GRACE and FORMOSAT-3/COSMIC, Terrestrial, Atmospheric and Oceanic Sciences, 20(1), 35-50.

Wickert J (2002) Das CHAMP-Radiookkultationsexperiment: Algorithmen, Prozessierungssystem und erste Ergebnisse, Scientific Technical Report 02/07, GFZ, Potsdam. 
Climatic Change, revised manuscript

Wickert J (2004) Comparison of vertical refractivity and temperature profiles from CHAMP with radiosonde measurements. Scientific Report 04-09. Danish Meteorological Institute, Copenhagen.

WMO (1957) Definition of Tropopause. Geneva. World Meteorological Organisation, Geneva. 
Table 1: The subdivision of Australia into latitude zones for the analysis of the tropopause parameters.

\begin{tabular}{|l|c|}
\hline \multicolumn{1}{|c|}{ Zone } & Latitudes \\
\hline Tropics & $8^{\circ} \mathrm{S}-20^{\circ} \mathrm{S}$ \\
\hline Subtropics & $20^{\circ} \mathrm{S}-40^{\circ} \mathrm{S}$ \\
\hline Mid-latitudes & $40^{\circ} \mathrm{S}-45^{\circ} \mathrm{S}$ \\
\hline
\end{tabular}

Table 2: Tropopause height and temperature changes estimated by CHAMP and COSMIC between 2001 and 2008.

\begin{tabular}{|l|c|c|}
\hline \multicolumn{1}{|c|}{ Zone } & Height (m) & Temperature (K) \\
\hline Tropics & $2.8 \pm 1.2$ & $-0.016 \pm 0.005$ \\
\hline Subtropics & $1.8 \pm 1.6$ & $-0.042 \pm 0.007$ \\
\hline Mid-latitudes & $0.9 \pm 1.2$ & $-0.002 \pm 0.007$ \\
\hline Australia & $4.8 \pm 1.3$ & $-0.019 \pm 0.007$ \\
\hline
\end{tabular}

Table 3: Tropopause height and temperature changes estimated by CHAMP (2001-2008) and COSMIC (July 2006) .

\begin{tabular}{|l|c|c|}
\hline \multicolumn{1}{|c|}{ Zone } & Height (m) & Temperature (K) \\
\hline Tropics & $3.4 \pm 0.6$ & $-0.016 \pm 0.005$ \\
\hline Subtropics & $1.9 \pm 1.2$ & $-0.018 \pm 0.008$ \\
\hline Mid-latitudes & $-2.4 \pm 1.6$ & $0.053 \pm 0.014$ \\
\hline Australia & $4.7 \pm 1.1$ & $-0.017 \pm 0.005$ \\
\hline
\end{tabular}




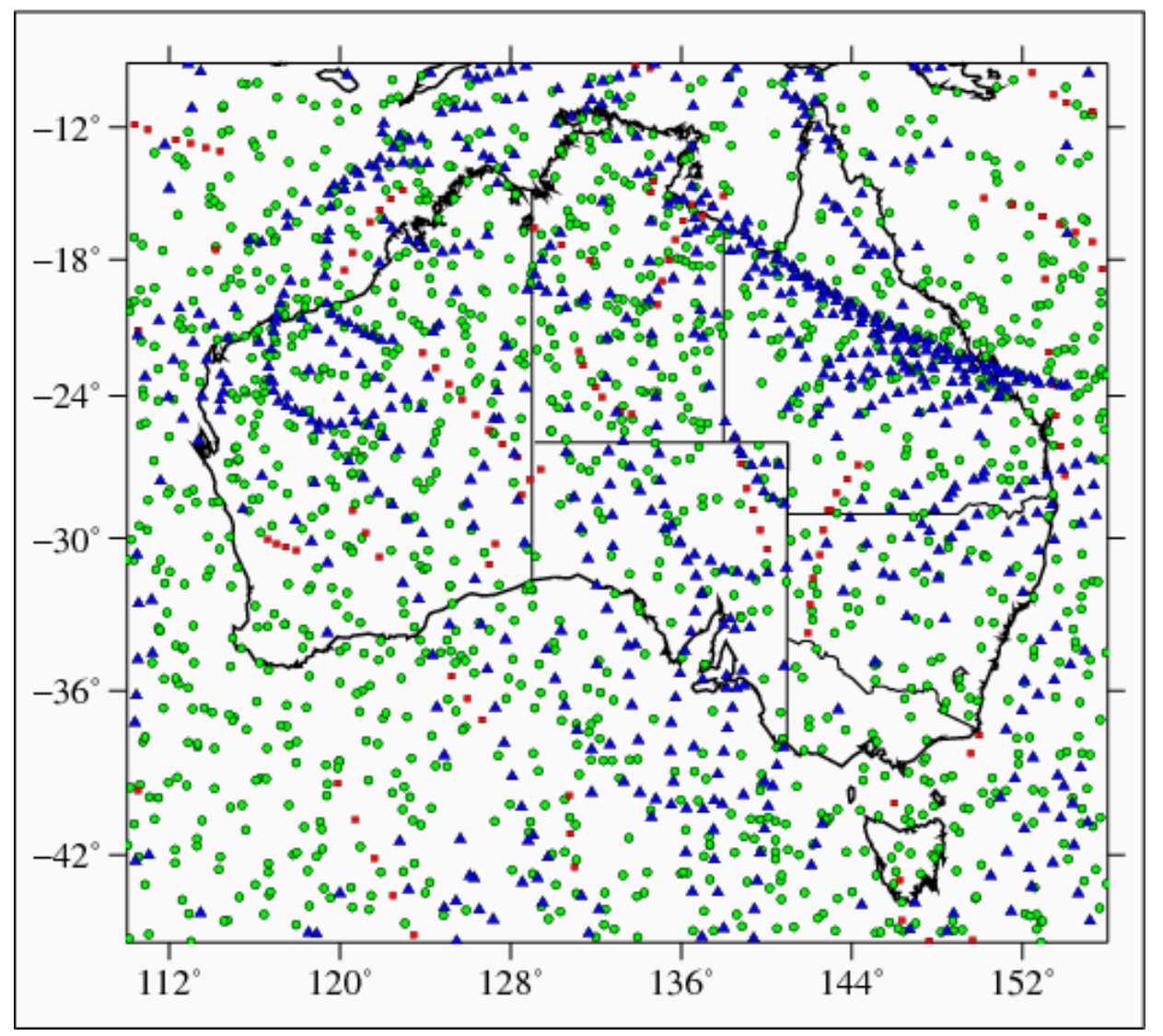

Figure 1: The locations of radio occultation positions for the year 2006 as measured by the COSMIC (green circles), CHAMP (red squares) and GRACE (blue triangles) satellites.

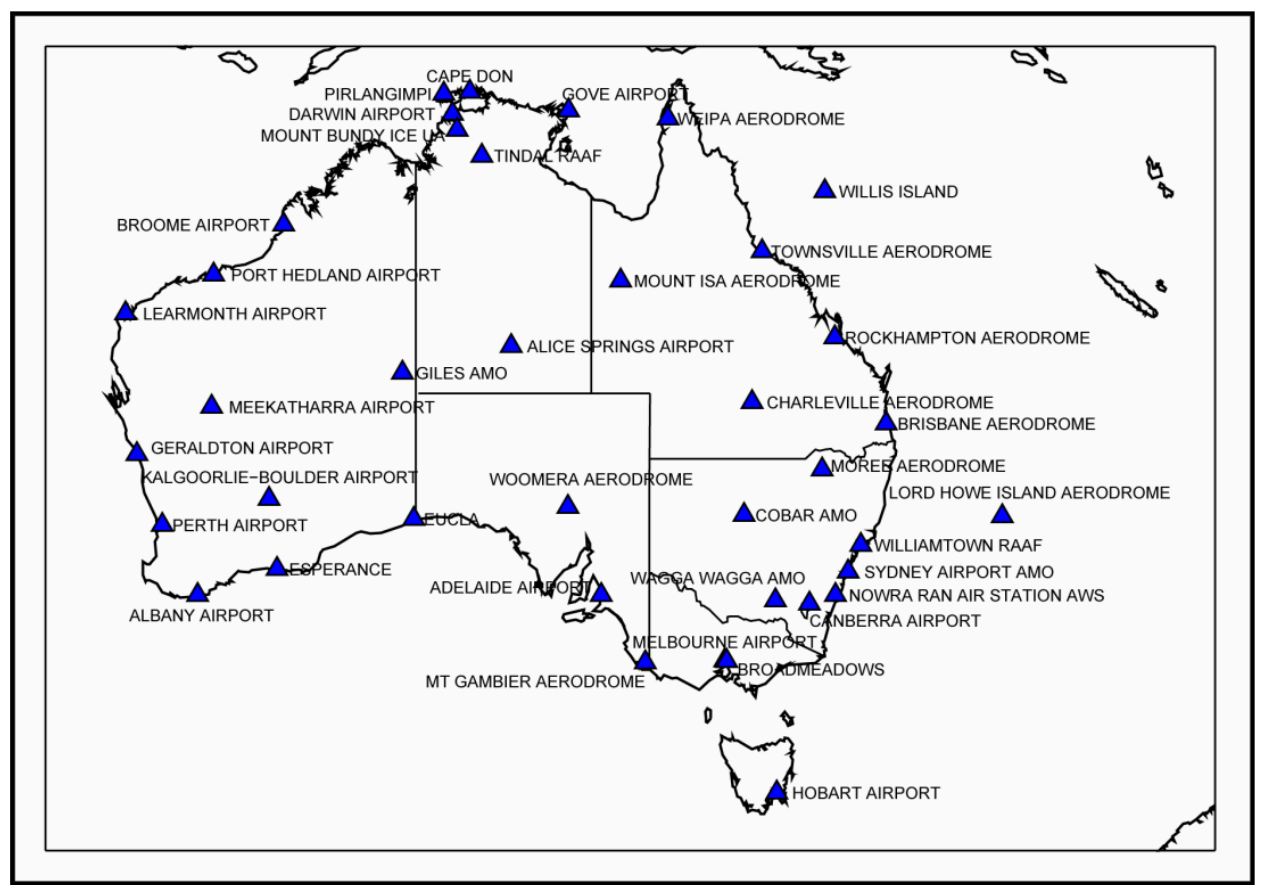

Figure 2: Radiosonde stations in Australia. 


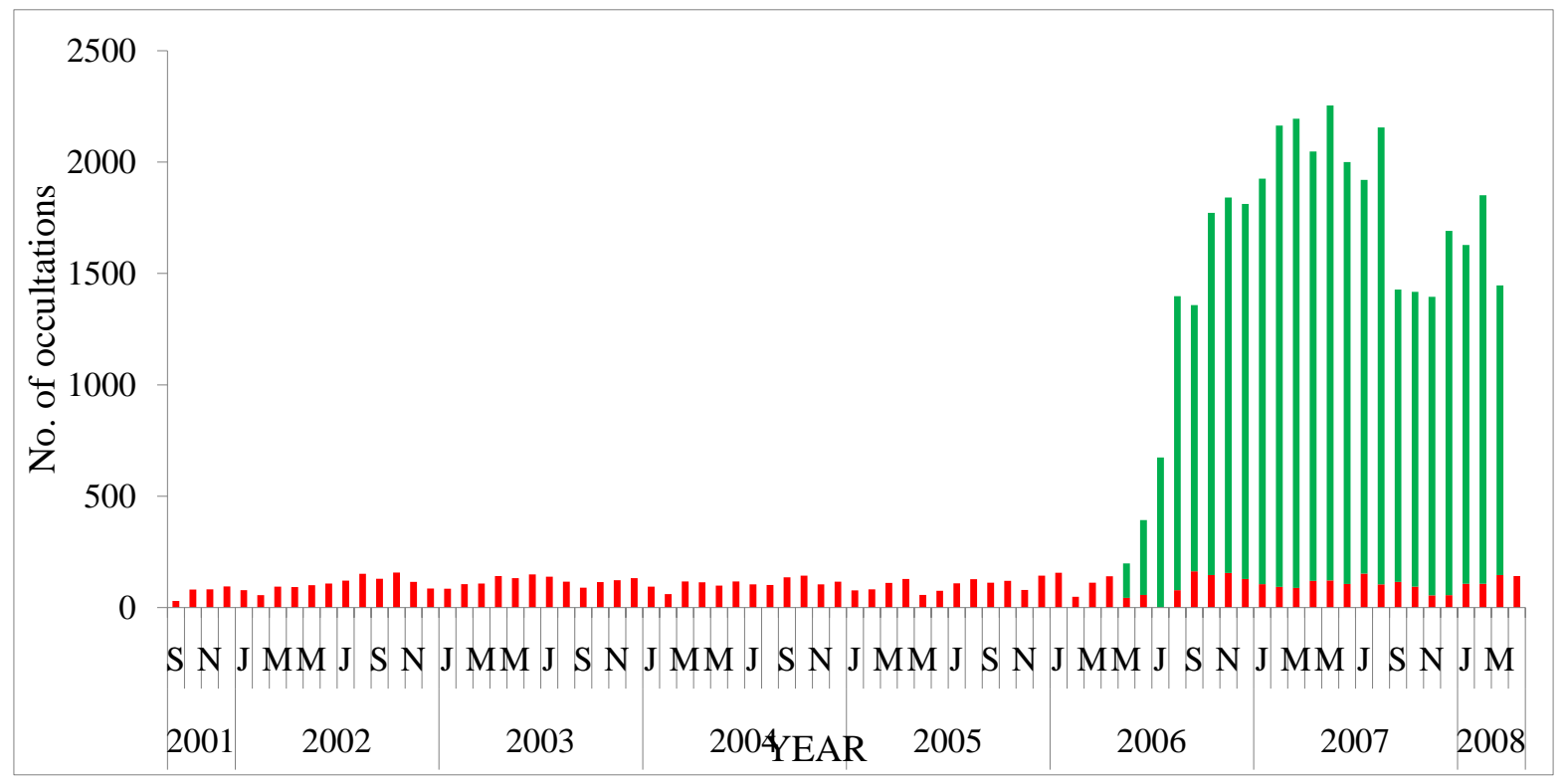

Figure 3: Number of CHAMP (red) and COSMIC (green) RO profiles obtained between September 2001 and April 2008.

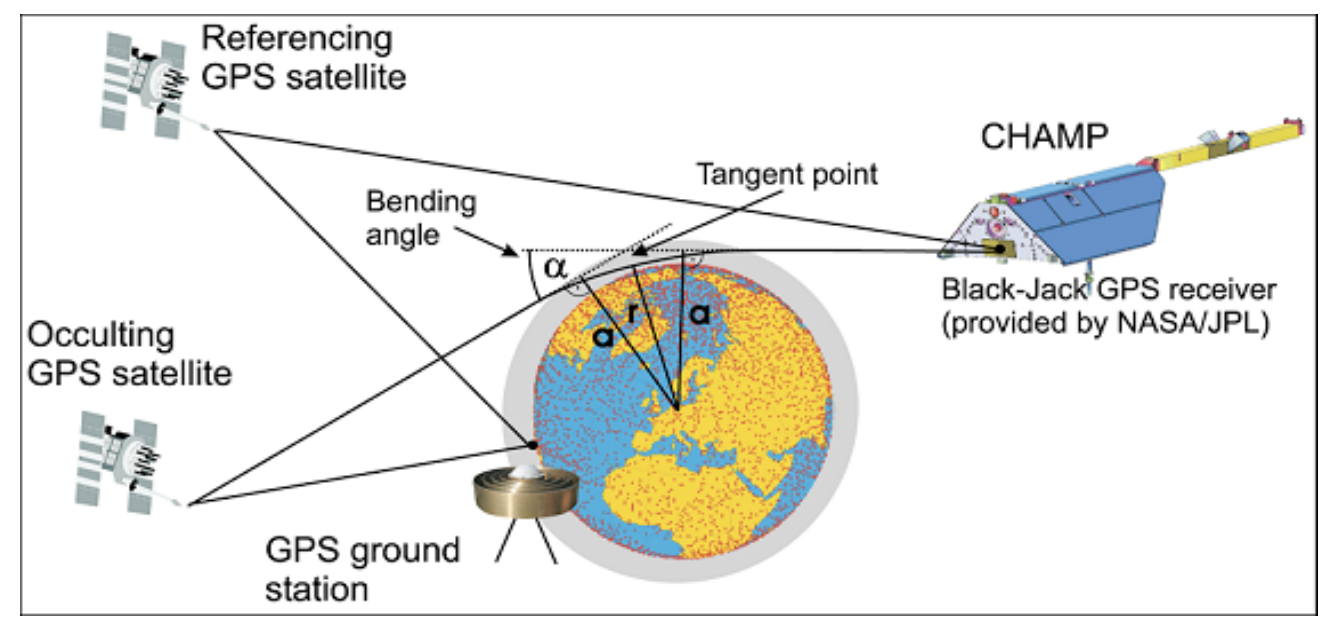

Figure 4: The geometry of a typical LEO satellite (here the CHAMP satellite), ray paths and ground stations as required for the GNSS radio occultation method (Wickert et al., 2004). 


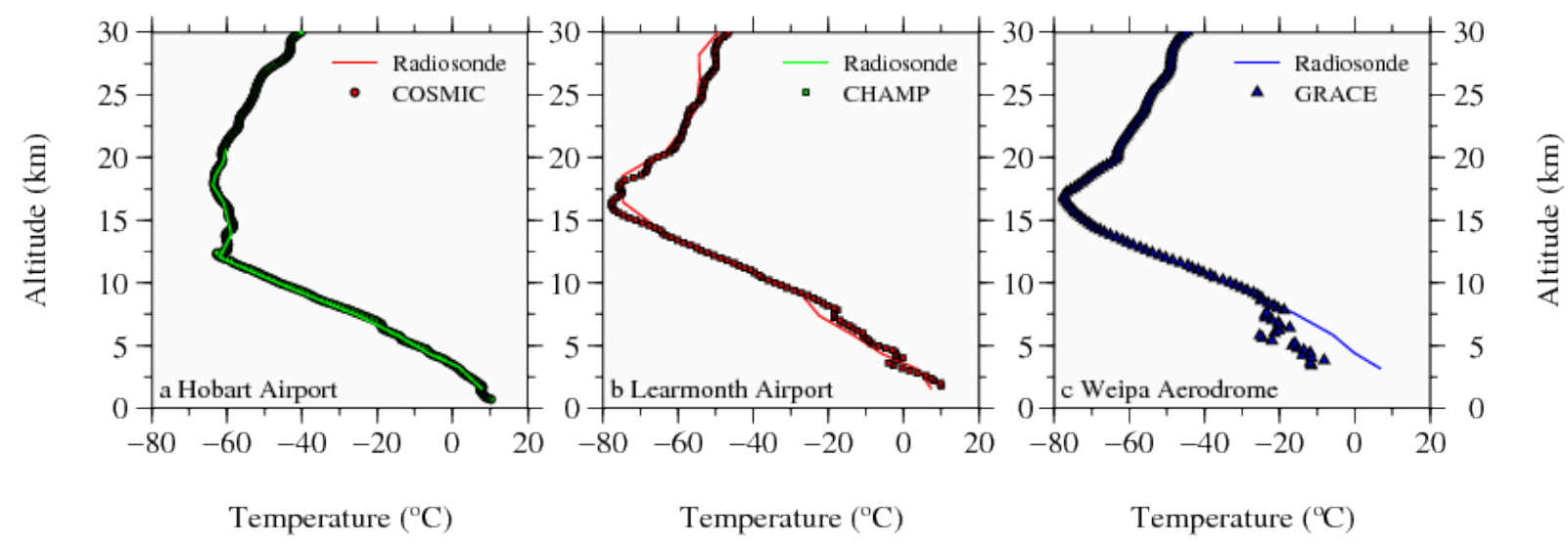

Figure 5: Comparing radiosonde profiles and results from satellite RO soundings observed on (a) 20 December 2006 over Hobart Airport $\left(42.89^{\circ} \mathrm{S}, 147.50^{\circ} \mathrm{E}\right)$ for COSMIC RO data, (b) 14 June 2005 over Learmonth Airport $\left(22.24^{\circ} \mathrm{S}, 114.09^{\circ} \mathrm{E}\right)$ for CHAMP RO data, and (c) 8 September 2006 over Weipa Aerodrome $\left(12.6778^{\circ} \mathrm{S}, 141.9208^{\circ} \mathrm{E}\right)$ for GRACE RO data. Altitudes are above mean sea level (AMSL).
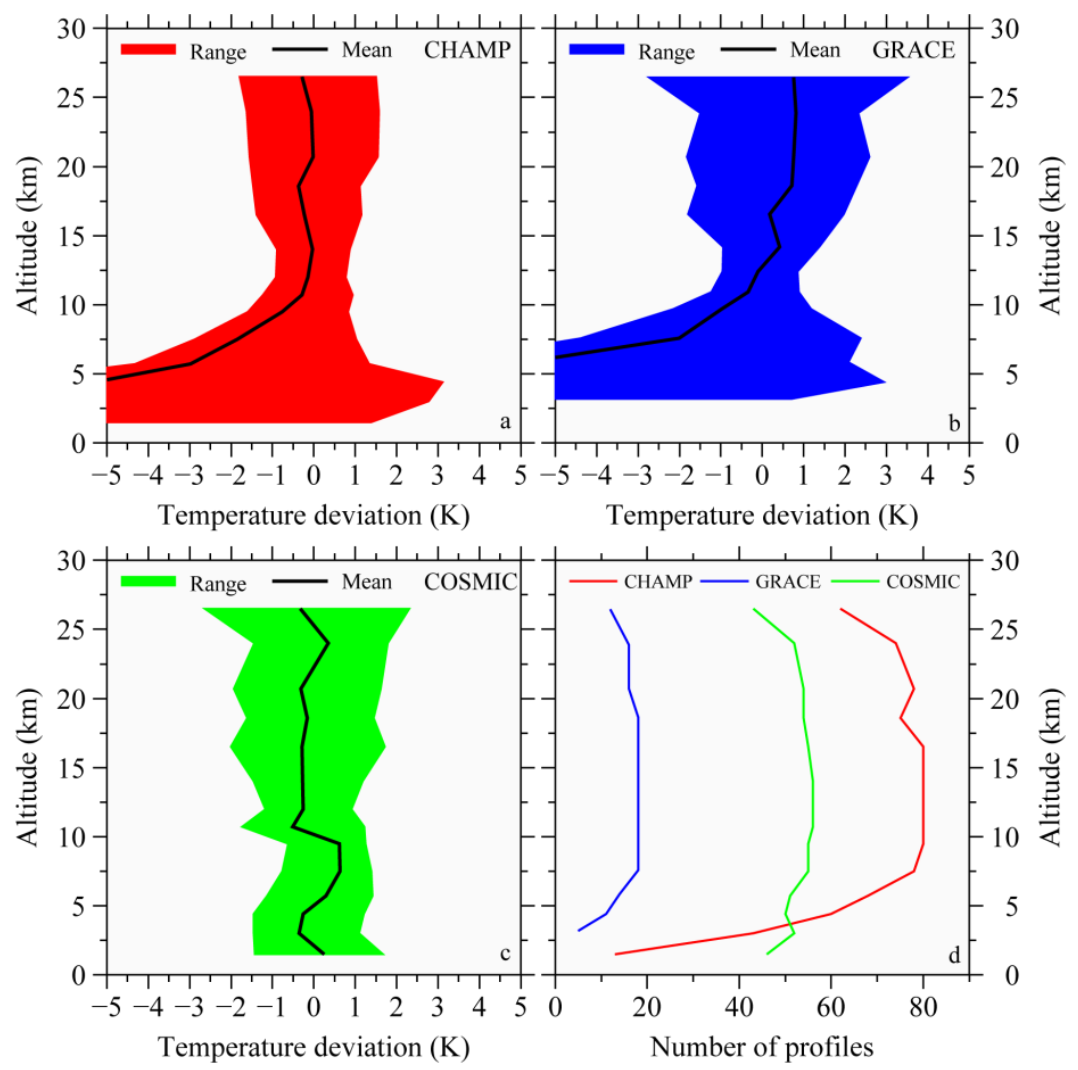

Figure 6: Comparison between satellite radio occultation (RO) and radiosonde temperature measurements over Australia. The criteria for the employed RO profiles are outlined in the text. (a) Comparison of CHAMP and radiosonde temperatures estimates for September 2001 to December 2006. (b) GRACE RO profiles from January 2006 to October 2007. (c) COSMIC RO profiles from April 2006 to December 2006. (d) Numbers of RO profiles used. 

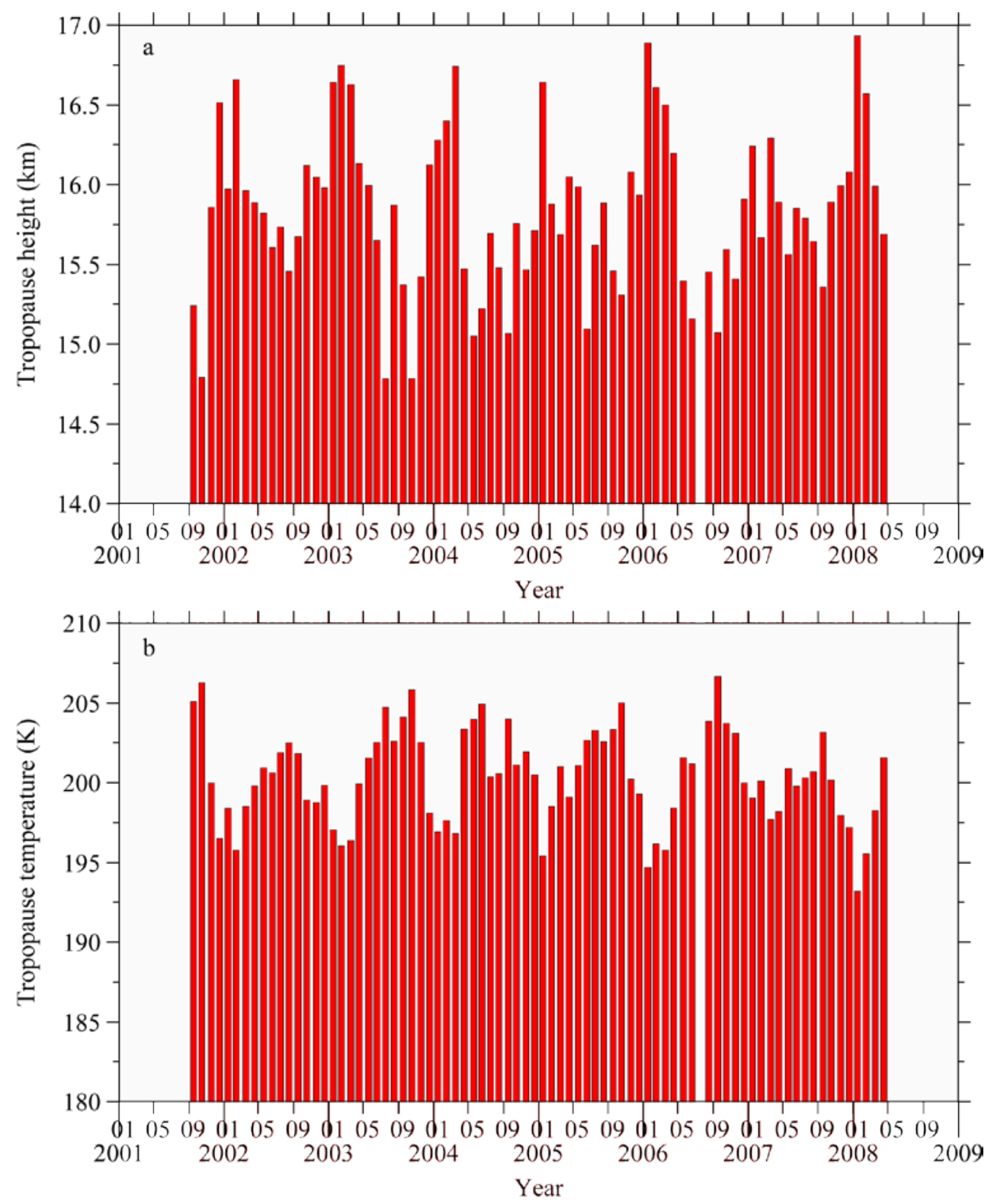

Figure 7: (a) Tropopause heights and (b) tropopause temperatures for Australia as found by the CHAMP RO data for the period between 2001 and 2008. 
Climatic Change, revised manuscript
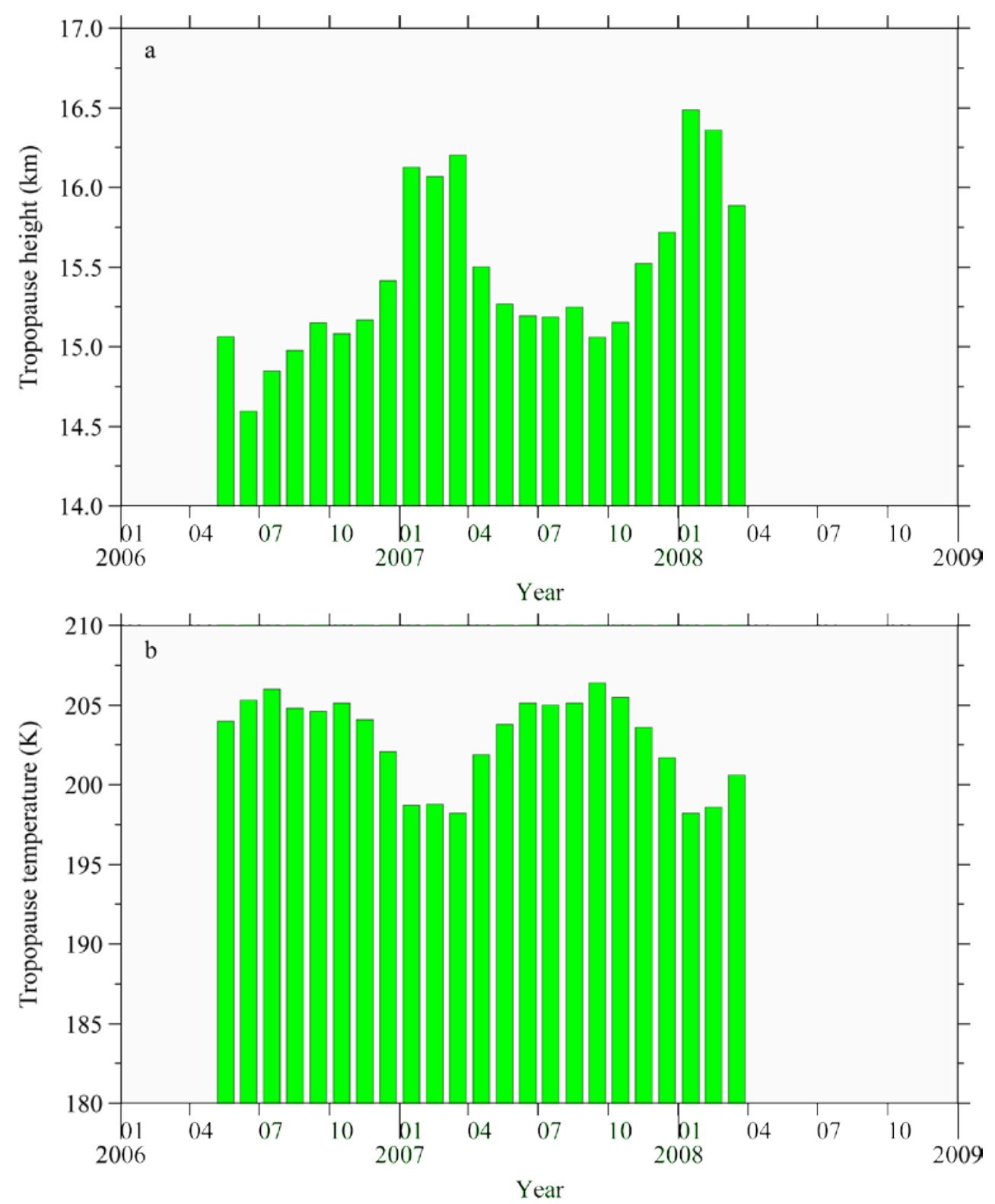

Figure 8: (a) Tropopause heights and (b) temperatures for Australia as a whole, as found by the COSMIC RO data for the period between 2006 and 2008. 
Climatic Change, revised manuscript
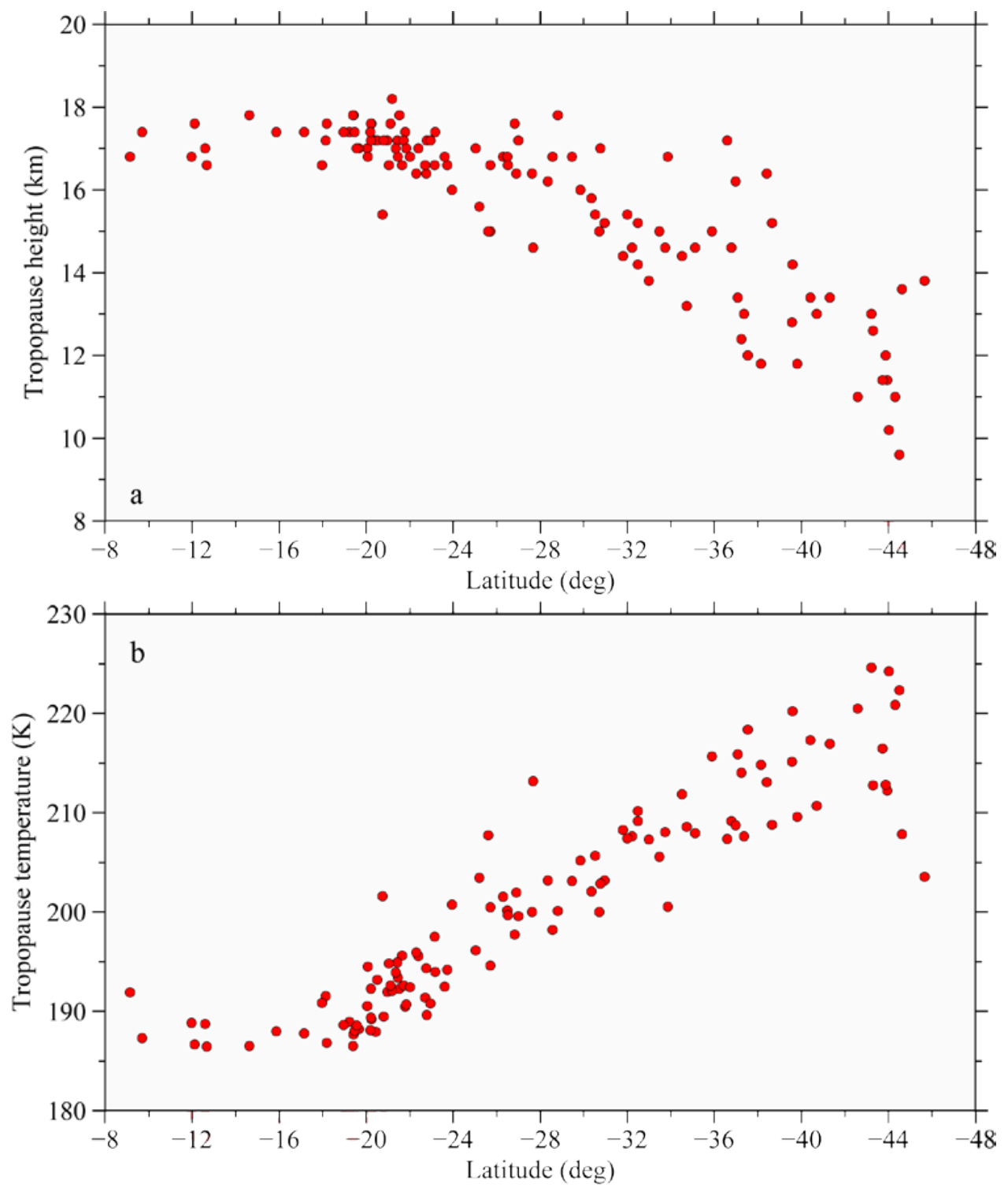

Figure 9: Tropopause height (a) and temperature (b) as derived from CHAMP observations during December 2004. 
Climatic Change, revised manuscript
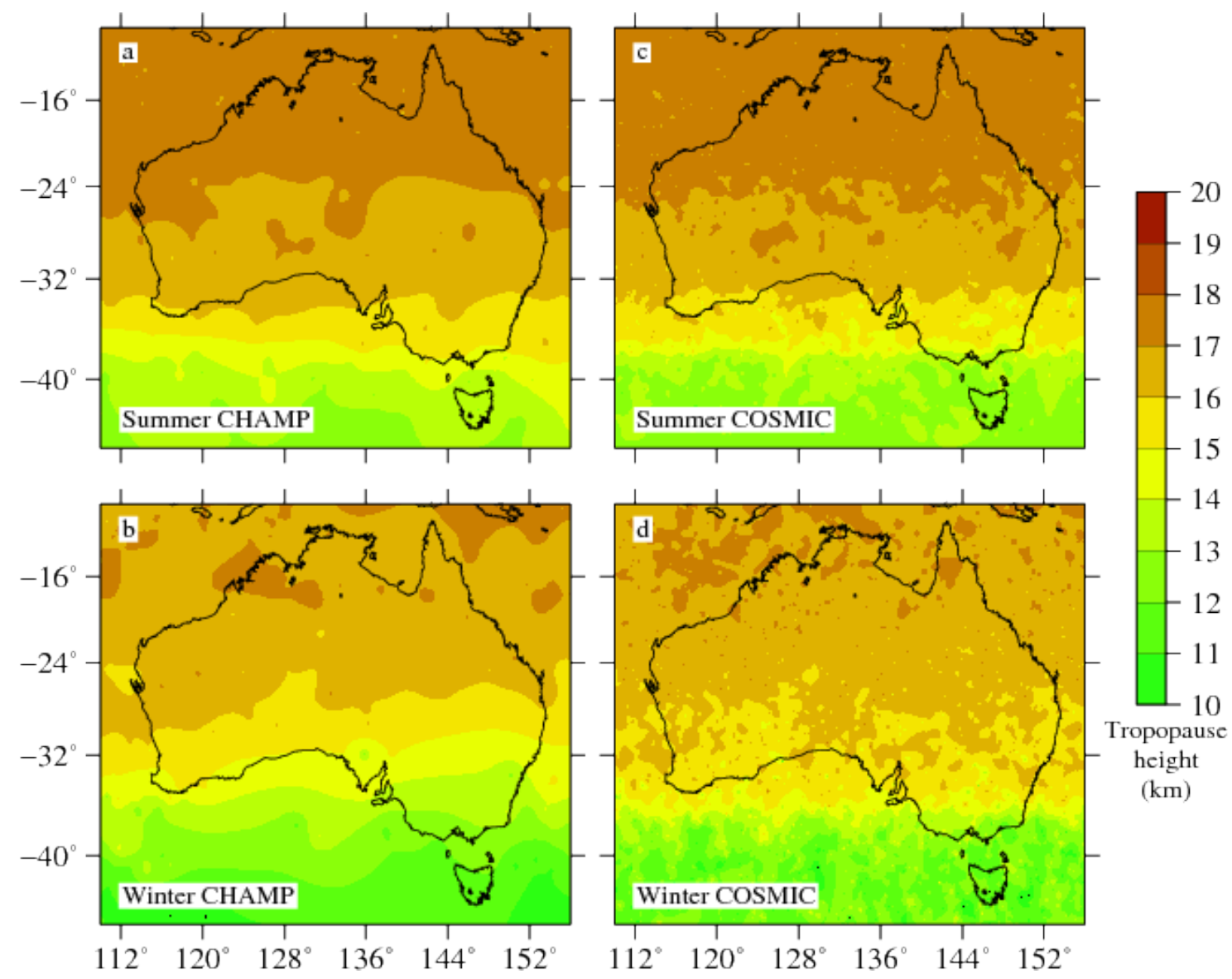

Figure 10: Tropopause height (in $\mathrm{km}$ ) derived from CHAMP and COSMIC RO data from between 2006 - 2007. (a) CHAMP results for summer, (b) CHAMP results for winter, (c) COSMIC results for summer, and (d) COSMIC results for winter. 
Climatic Change, revised manuscript

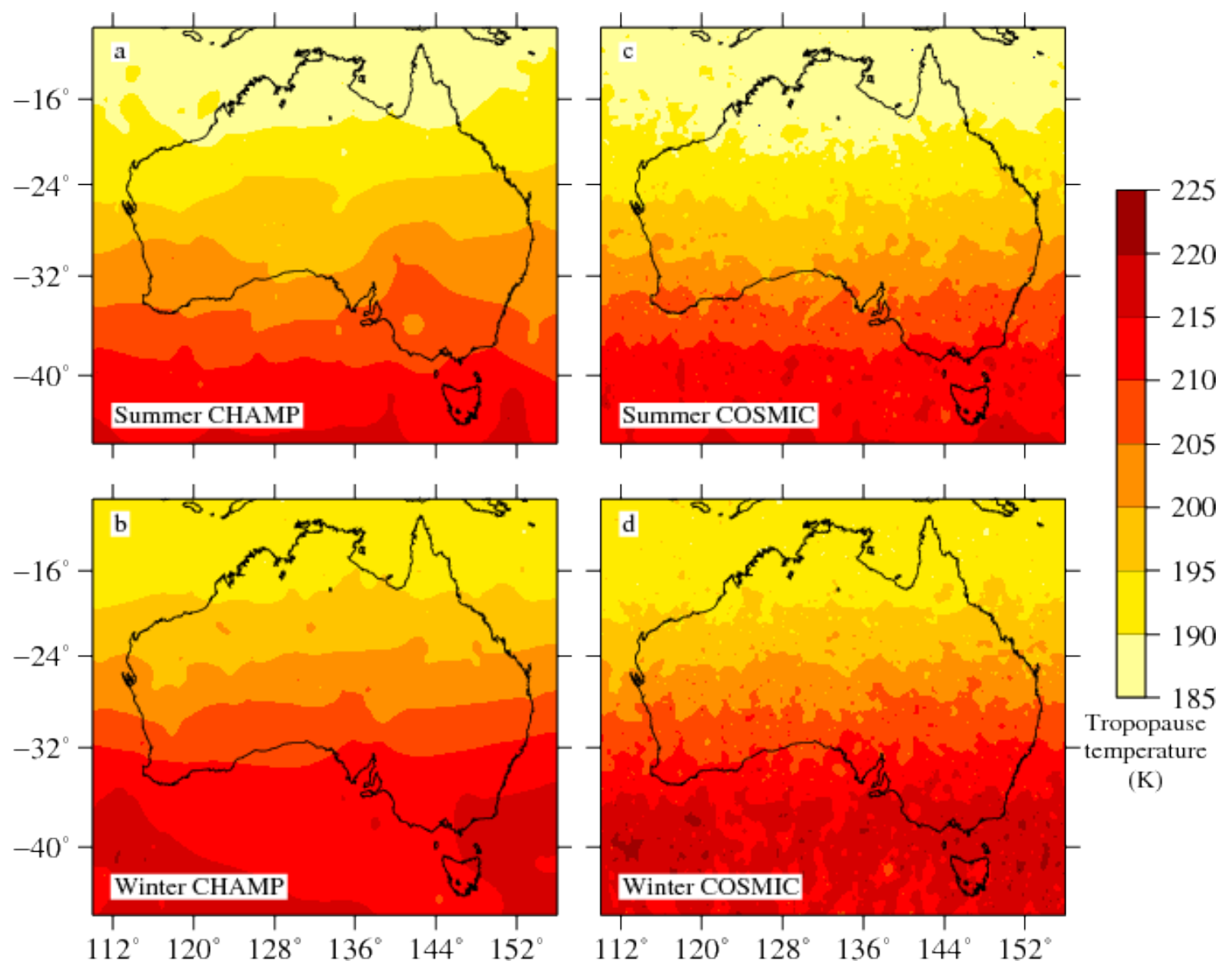

Figure 11: Tropopause temperature (in K) derived from CHAMP and COSMIC RO data from between 2006 - 2007. (a) CHAMP results for summer, (b) CHAMP results for winter, (c) COSMIC results for summer, and (d) COSMIC results for winter. 
Climatic Change, revised manuscript

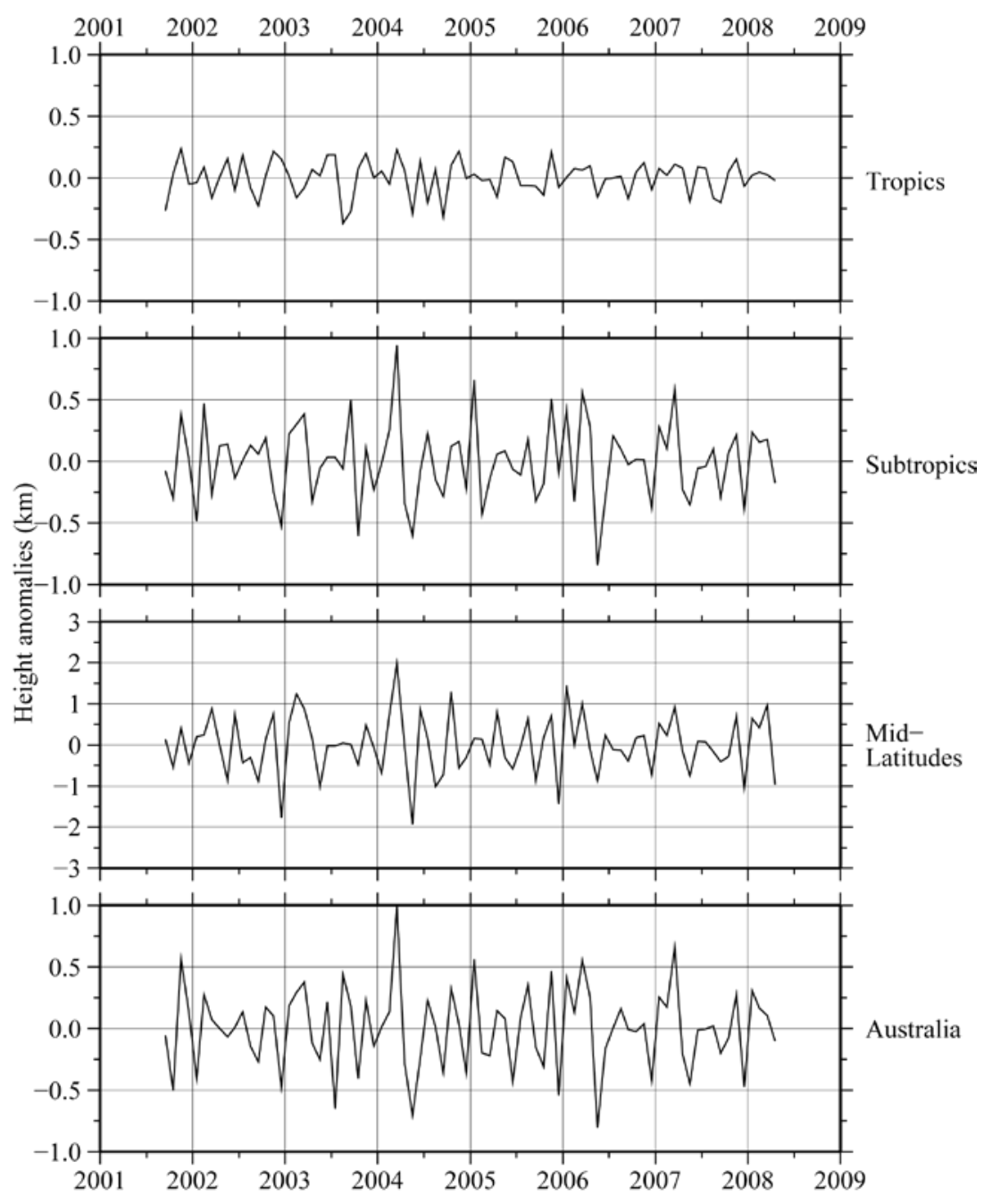

Figure 12: Tropopause height anomalies estimated from the combined CHAMP and COSMIC RO data for between September 2001 and April 2008. 
Climatic Change, revised manuscript

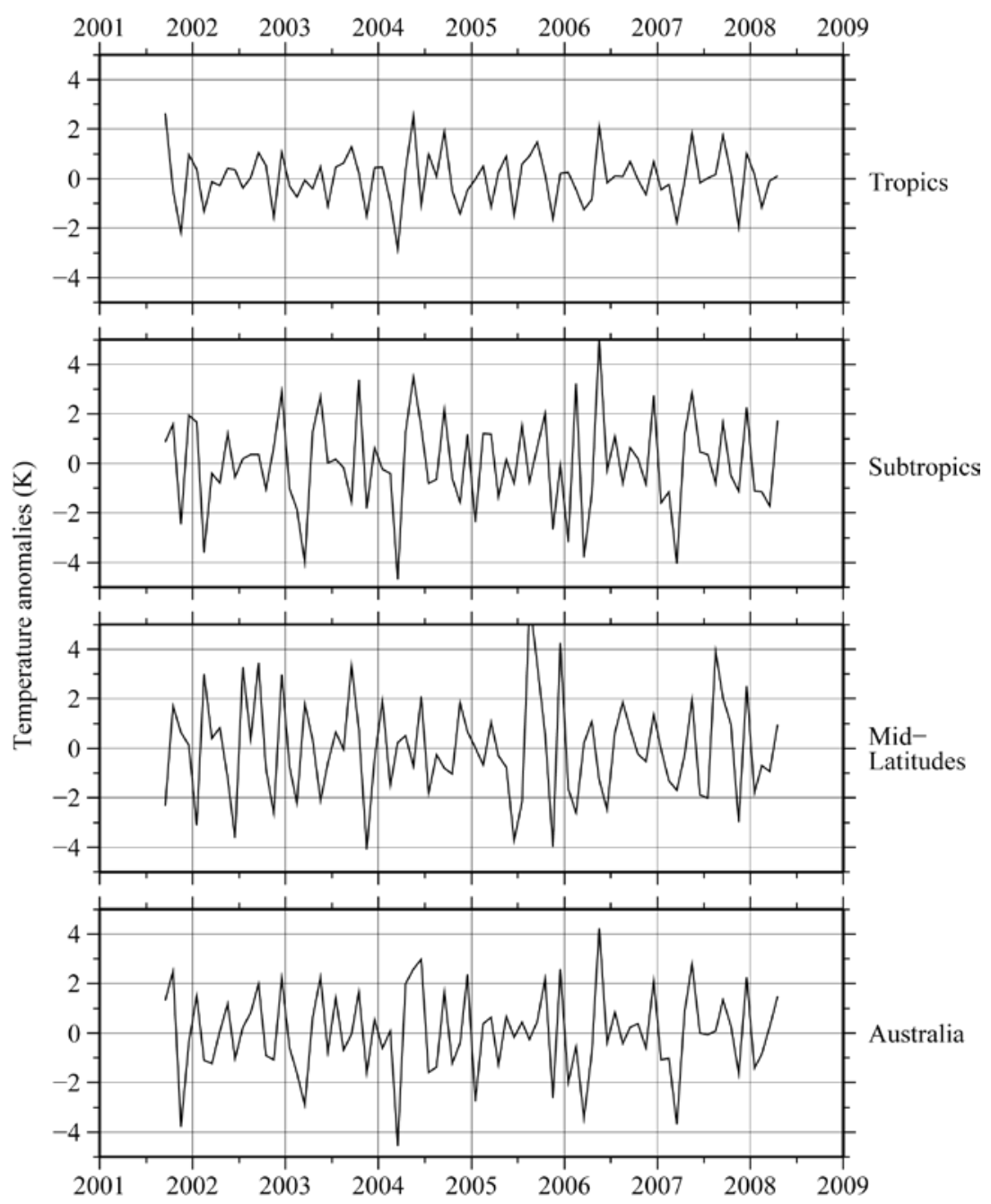

Figure 13: Tropopause temperature anomalies estimated from combined CHAMP and COSMIC RO data for between September 2001 and April 2008. 
Climatic Change, revised manuscript
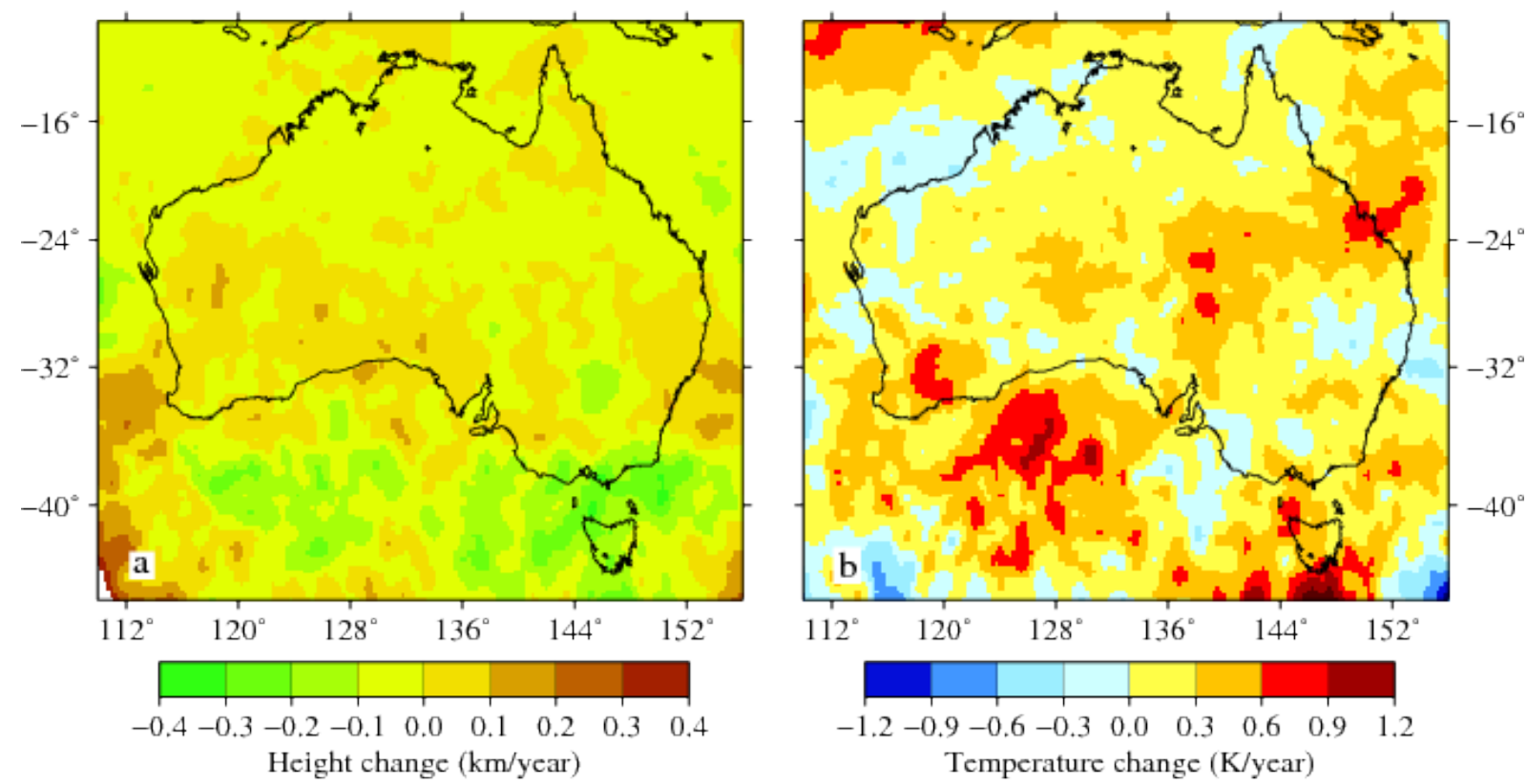

Figure 14: Rate of change in (a) the tropopause height and (b) tropopause temperature between September 2001 and April 2008. 